\title{
TEACHER RESEARCH: PRACTICE, CHALLENGES AND PROSPECT FOR IMPROVEMENT: AN EMPIRICAL STUDY FROM OMAN
}

\author{
Sulaiman Al-Ghattami, PhD \\ University of Edinburgh, \\ Assistant Professor College of Education, Sultan Qaboos University \\ Suleiman Al-Husseini, PhD \\ University of Leeds, \\ Researcher, University of Nizwa, Sultanate of Oman.
}

\begin{abstract}
This study investigates teachers' conceptions of engagement with, and in, teacher research (TR) in the Sultanate of Oman. The data collected through interviews and questionnaires reveals that TR is not yet common practice in Omani schools. To make TR a sustainable mainstream activity within school environments should entail improving teachers' concepts, attitudes, and understandings of the role of TR in the development of educational system and for their own professional development. Teachers should also be provided with logistical requirements and practical conditions that help them become active and competent practitioner researchers.
\end{abstract}

Keywords: Teacher research, teacher's concepts, attitudes, institutional support, change making

\section{Introduction}

Teacher research (TR) was first presented in the 1970s by Lawrence Stenhouse and has recently been introduced to the school system of the Sultanate of Oman. Since the commencement of the 2007/8 academic year, teachers at all grades, specializations, genders and districts are encouraged to conduct academic research, which has also become a main subject in PostBasic Education (PBE) schools (Year 12). This research curriculum focuses on providing students with opportunities to develop their own learning through self-reliance (Ministry of Education, 2009). To promote teacher engagement in research practice, two annual national competitions, one for 
each students and teachers, are organised by the Ministry of Education, with the winning research projects or papers acknowledged and rewarded.

Most of the teachers in general education in Oman, are Omanis (male and female) who graduate from educational colleges and universities both inside and outside Oman. Teacher training in Oman includes research skills courses and trainees are required to do a final year research project. Therefore, these teachers are familiar with research. The questions which still remain are whether they practice research and read research articles after graduation from university? Also, should introducing a research culture into schools in Oman make the target educators competent researchers by default? To the best knowledge of the researchers, studies on TR in Oman are limited to Alfarsi (2006) and Borg (2007 \& 2013) who emphasize the need for follow up research. This study then aims at contributing to the findings of previous research and filling any potential gaps in the understanding of school-teachers' conception, use and practice of TR in schools of the Ministry of Education, and enabling stakeholders to make informed decisions for the improvement of initiative and development of policy.

To accomplish its target, the study poses the following research questions (RQs).

1. What is the teachers' perception of the role of research in the development of the Omani educational system?

2. To what extent do teachers engage in research?

3. What is the teachers' attitude towards participation in research?

4. What hinders teachers from research and what do they perceive assists them to overcome such obstacles?

\section{Background to General Education in Oman}

The Ministry of Education has been the main provider of pre-tertiary education in Oman. At present, the system contains two concepts: Basic Education (BE) and PBE (Post-Basic Education). BE was launched in 1998/99 to replace GE, which was a twelve-year program divided into three stages: Elementary- 6 years, Preparatory- 3 years and Secondary- 3 years. BE has two stages: Cycle 1 (Year 1-Year 4) and Cycle 2 (Year 5-10). It provides basic educational needs as to information, aspects of knowledge and skills, as well as the development of objectives and values that enable the learners to proceed in education and training according to their tendencies, readiness and abilities (Ministry of Education, 2009).

PBE encompasses Years 11 and 12 aiming to further develop students' basic skills as well as providing them with job skills and career planning techniques to enable them to become active members of society, and to be able to take advantage of opportunities in education, training and 
work after school. A major distinguishing factor of PBE is that it seeks to enable students to become effective users of self-learning and research skills (Ministry of Education, 2009).

\section{Literature review}

Unlike many ideas in education which vanish once confronted by new competing ideas, teacher research (TR) that was proposed by Stenhouse has proven itself and the call for teacher engagement in research has become even stronger nowadays (Dana \& Yendol-Silva, 2003; Simms, 2013 and Borg, 2013). The concept is accepted in many education systems around the world and gains attention from researchers and theorists of various disciplines and backgrounds so that, as Reise-Jorge (2007, p 403) notes "the diversity of contexts, aspirations, epistemological and methodological orientations of teacher-research makes it difficult, if not impossible; to arrive at a general agreed definition of the concept". It is perceptible that TR is discussed in literature under different concepts such as teacher-research (Lytle and Cochran-Smith, 1989; Rust, 2009), teachers' research engagement (Borg, 2007), enquiry-oriented teacher education (Lucas, 1988), classroom research (Campbell, 2013), practitioner researcher (Robson, 1993), and teacher self-study (Roulston Legette, DeLoach, Bukhalter-Pittman, Cory, \& Grenier, 2005). Furthermore, TR also gains elaboration in publications on main stream education research e.g. Robson (1993); language teaching research e.g. Nunan (1992) and Borg, (2013); action research e.g. Parsons and Brown (2002), Ponte (2010), Dobber, Akkerman, Verloop, \& Vermunt (2012) \& Mills (2003); teacher education e.g. Loughran (2010); and teacher professional development e.g. Snow-Gerono (2005). The core concern of all these concepts, as Borg (2013 p 8) concludes, is "inquiry conducted by teachers in their own professional contexts".

Available literature investigates TR utilizing two methodologies. The first tract considers TR in pre-service teacher training either at degree or higher education levels. Examples of studies focussing on university courses in TR are Dobber et al, (2012), Reise-Jorge (2007), Loughran (2010), Simms (2013) and Donnell \& Harper (2005). The second track, within which the present study falls, contemplates TR done by teachers while in-service. Within this category, come studies that are undertaken by university academics aiming at engaging a group of school teachers in research to explore to what extent what they gain from such experience, reflects on their classroom practices, knowledge and professional developments. Examples of these types of studies are Henson (2001); Atay (2008); Chandler-Olcott (2002); Jurastaite-Harbison and Rex (2005) and Maeijer, Oolbekkink, Meirink, \& Ditte (2013). There are also studies e.g. Beycioglu, Ozer, Niyazi \& Ugurlu (2010) and Alfarisy (2006) that focus on teachers not necessary 
engaged in TR, trying to understand their perceptions of TR, the difficulties they encounter, and the support they require in order to become practitioners in research. In addition, there are studies which discuss TR on educational and/or social theoretical basis' attempting to establish a link between theory and practice in education. Examples of these types of studies are Ponte (2010); Lytle \& Cochran-Smith (1989); Loughran (2010); AdomBent, Fischer, Godemann, Herzig, Otte, Rieckmann \& Timma (2014); Rust (2009); Avalos (2011) and Dana, Gimbert, \& Silva (2001).

Teacher-research is defined as "systematic and intentional inquiry carried out by teachers in their schools and classroom" (Lytle \& CochranSmith, 1994 p 24) to achieve different aims such as teacher professional development (Lytle and Cochran-Smith, 1994; Simms, 2013 and Dana et al, 2001), reflective teaching (Parsons \& Brown, 2002), democracy in education (Buxton, Kayumova \& Allexsaht-Snider, 2013), school reform (Dana et al, 2001); making classroom teaching evidence-based (Verma \& Mallick, 1999; Kincheloe, 1991 and Borg, 2007 \& 2013), informed policy making and establishing a balance between university based theoretical educational research and practical classroom practice (Rust, 2009). Certainly, none of the previously listed aims are out of the scope of argumentative debates among specialists, yet engagement in TR might conclude with achieving one or more of them.

For example, researchers affirm that TR is a vehicle for teacher professional development (Dana et $\mathrm{al}_{2}$ 2001) which basically includes the existing knowledge a teacher possesses, how to gain new knowledge, and how to transform that knowledge into classroom practice to the benefit of the students (Avalos, 2011). Specialists in teacher professional development prefer TR to the traditional methods of professional development which are usually administered in terms of short workshops conducted by insiders or outsiders but do not typically relate to classroom practice. It is argued that TR makes professional development an on-going process fostering the teacher's ability to become an independent learner, inquirer and knowledge generator (Borko, Jacobs \& Koeliner, 2010 and Meijer et al, 2013). It is also argued that the impact of engagement in TR on teachers' professional development is evident in enhancing teacher creativity, self-confidence, and producing the knowledge the teacher needs in the classroom (Borg, 2007; Dobber et al, 2012 and Parsons \& Brown, 2002).

Furthermore, TR intersects, at different points, with another component of teacher professional development, namely reflective teaching (also called reflective practice). First, the teacher's attention in both TR and reflective practice is directed towards what happens inside the classroom and the teacher-students interchange for the sake of improvement of the students' accomplishment. Second, in both situations, teachers collect data about his or 
her students using similar tools, such as observation, interviews, exams results and records. Third, reflection is a default end result of research position, in that the researcher teacher is required to sit down at the end of the research and consider how to use the research results for the development of the students and the improvement of classroom instruction (Parsons \& Brown, 2002; Avalos, 2011; Loughran, 2010).

The debate on academy and TR, which is still on-going, demonstrates a serious gap between theory and practice in education. On one hand, teachers question the value of academic research, maintaining that research done by academics is too theoretical and of indirect implication to the teaching reality (Beycioglu et al, 2010; Bevan, 2004; Ektz, 2006; and Mortimore, 2000). Teachers also maintain that academic research cannot replace the practical experience that teachers gain from day-to-day involvement in classroom practice. Many teachers are consequently not interested in any engagement in research. Closing the gap between theory and practice, and establishing a balance between school and university should be achieved, as McLaughlin (2004) maintains, by encouraging teachers to do research. Not only that, but taking part in research should make teachers' voices heard and should give them the opportunity to express their points of view. It is also advocated to make education more democratic (Cochran-Smith \& Lytle, 1990). This view is supported by the opinion that classroom research makes classroom teaching evidence-based (Verma \& Mallick, 1999; Kincheloe, 1991 and Borg, 2007). It is believed that a classroom teacher is not only a source of authentic and valuable knowledge about what goes on in the classroom, but also the most reliable source of such information. Supporters of this view dictate that a teacher who spends most of the time with the students in the classroom is more qualified to speak about them than assigning that authority to external researchers or experts who scarcely stay in the classroom.

However, not all specialists believe that TR is reliable when it comes to its contribution to theory, planning and decision making (Simms, 2013). Anderson \& Herr (1999) and Zeichner (2003) maintain that an explicit distrust exists in both the UK and USA of TR results and that some research by teachers in these countries is incomplete and therefore invalid (Meijer et al, 2013). Nuna (1992 \& 1997); Murray (1992) and Myer (1985) affirm that TR should be evaluated in light of the criteria of academic research taught and practiced in universities, and any work not meeting academic research standards should not be looked at as research. Borg (2013, p 19) states "irrespective of the purpose of the inquiry, if it is to inform instructional decision making then confidence must exist in the trustworthiness of the findings". In reality, however, as Alfarisy (2006) and Reise-Jorge (2007) 
note, not many teachers are familiar with and implement academic research standards in their research attempts.

On the other hand, Allwright (1997), Cochran-Smith \& Lytle (1990) and Richardson (1994) advocate a less impressive opinion towards TR requirements. They advocate that teachers should not be asked to do research identical to academic research nor should TR be evaluated against criteria set up for academic research. This point of view is based upon a number of justifications, at the top of which is that teachers are too busy with teaching and have limited opportunities to study academic research methodologies that are usually offered in independent courses in universities. It is also argued that academic research methodologies can be replaced by one that teachers themselves derive from their classroom practices and school context. Finally, sustaining continuity in TR should not be confronted by challenging requirements which may prove beyond teachers' capacity to fulfil. It is also argued that TR results should be used for improving the researching teachers' capacities and the schools in which they teach, rather than to generalize their results. This view of the purpose of teacher research is relevant to that of Berthoff (1987) and Britton (1987) who contend that TR is a reflexive practice, so it does not require research methodology and data collection, but is rather an inspiration for teachers to notice what occurs in the classroom (Reise-Jorge, 2007). The problem with this conception of the purpose of TR is that it contradicts with the teachers' perception that TR results should be used for the improvement of education, and unless that is done, teachers would not like to take part in TR.

However, both university-school partnerships (Ponte, 2010) and collaborative research (Meijer et al, 2013; Ponte, 2013 and Anderson \& Herr, 1999), are ideas brought forward to sustain quality and continuity within TR practice. There is a contentment that TR is more likely to yield satisfactory results when school teachers are engaged in research projects supervised by university lecturers (Dobber et al, 2012). In this case university lecturers provide research knowledge that teachers need to proceed with research, and overcome the challenges that they might face. In addition, university academics provide theoretical knowledge, while school teachers provide practical knowledge, assisting in closing the gap between theory and practice in educational research (Beycioglu et al, 2010).

Collaborative research means that teachers work in teams, rather than individually, to do research. It is believed that collaborative research encourages teachers to share responsibility, interchange information and experiences, distribute tasks and secure research quality (Meijer et al, 2013; 2009; Ponte, 2010; Anderson \& Herr, 1999 and Lytle \& Cochran-Smith, 1989). However, collaboration also requires a support flow from the surrounding environment, especially from peers and school management to 
the researcher teacher or group of teachers (Ponte, 2013; Reis-Jorge, 2007; Snow-Gerono, 2005 and Meijer et al, 2013). Such cooperation enables teacher researchers to verify ideas, gain data and implement results. Regrettably, not all schools and educational systems provide the required support, nor do they adopt the recommendations of teacher researches (Lytle and Cochran-Smith, 1989; Schulz, 2010; Borg, 2013 and Snow-Gerono, 2005). Meeting teacher research efforts unsympathetically is counterproductive because researcher teachers are pragmatic, which means that they do not do research as a target by itself, but as a means for securing improvement in teaching and making changes in the educational system (Borg, 2013 Reis-Jorge, 2007). If education as an enterprise does not pay attention to research results and recommendations, then teachers will stop research. Alfarisy (2006) finds that only 16 teachers do TR out of 60 teachers who participated in his study. The teachers who did not do research believed that their schools had no plans for benefiting from their research results and recommendations.

All in all, a key issue in the literature remains that teachers' engagement in TR could be understood better when teachers' voices are heard, and their accounts of the highs and lows of the process are expressed and considered faithfully (Lytle \& Cochran-Smith, 1989; Borg, 2013 and Simms, 2013). This study, therefore, tries to contribute to the existing debate by exploring teachers' perceptions of TR and how to make it a mainstream practice in teachers' community.

\section{Methodology}

Data was collected by questionnaires and interviews from 580 school teachers working in 4 educational districts in Oman namely Muscat, AlDakhilya, Sharqya North and Al-Dhahira. Questionnaires are used in this study because this tool has been considered rather practical in education research for collecting data from a large number of participants (Robson, 1993, and Nunan, 1992). To achieve this purpose, a questionnaire was designed in both Arabic and English and distributed to 547 randomly selected school teachers, see Table 1 below. Equality in numbers of participants from each district was rather difficult to maintain and deemed unnecessary as the study does not attempt a comparative analysis. Prior to final distribution of the questionnaire, validity was checked by peer review then a random sample of 30 questionnaires was used to check reliability using Cronbach's Alpha which showed 90\%.

As to the analysis of the questionnaire, Sections 1,2 and 3 were analysed quantitatively using SPSS and the results are presented in the forthcoming section. Mean is used as an indicator of overall agreement with each statement. In this sense, Means from 1 to 2.5 = low agreement; more 
than 2.5 to $3.5=$ medium agreement and more than 3.5 to $5=$ high agreement. The open-ended questions were analysed qualitatively and he frequency of each answer was also calculated to provide information for:

a. teachers' perceptions of the role of research in educational system;

b. extent to which teachers engage in research;

c. teachers' attitudes towards doing research;

d. factors that hinder teachers from conducting research;

e. participants' suggestions to engage in and with research.

Interviews were conducted with 36 teachers other than those participating in the questionnaire in order to sustain triangulation. Interviewees were asked to elaborate upon the following points: what they think research is; whether they believe research is beneficial for teaching and learning; whether they would like to participate in research; whether they have research skill and MoE support for TR. The interviews took place in Arabic, some of them are audio recorded and transcribed. Data collected by interviews analysed and presented in the analysis section below.

Table 1: Number and percentage of teachers who participated in answering the questionnaire from each educational district.

\begin{tabular}{|c|c|c|c|c|c|c|}
\hline \multirow{2}{*}{$\begin{array}{c}\text { Educational } \\
\text { Region }\end{array}$} & \multicolumn{4}{|c|}{ Gender } & \multicolumn{2}{c|}{ Total } \\
\cline { 2 - 7 } & number & percentage & number & percentage & number & Percentage of the total \\
\hline Muscat & 44 & $33.6 \%$ & 87 & $66.4 \%$ & 131 & $24 \%$ \\
\hline Dakhilya & 83 & $43.7 \%$ & 107 & $56.3 \%$ & 190 & $34.7 \%$ \\
\hline Al-Dhahira & 98 & $43.4 \%$ & 128 & $56.6 \%$ & 226 & $41.3 \%$ \\
\hline Total & 225 & $41.1 \%$ & 322 & $58.9 \%$ & 547 & $\begin{array}{c}3.5 \% \text { of the whole } \\
\text { population of } 15,747 \\
\text { teachers in Oman when } \\
\text { the study was conducted. }\end{array}$ \\
\hline
\end{tabular}

\section{Analysis}

The data gathered by the interviews and questionnaires was analysed to answer the RQs. As explained earlier in the previous section, Means of responses to each degree of the five point scale categorised into three groups: from 1 to 2.5 = low agreement; more than 2.5 to 3.5 = medium agreement and more than 3.5 to 5 = high agreement. Relevant quotes from interviews and open-ended questions are presented.

1. Teachers' perceptions of the role of research in development of educational system in Oman

Analysis of interviews and questionnaire items 2, 3, 6, 14 \& 23 which provide answers to RQ1 reveal that participants have two contradicting perceptions regarding the role of research in development of the educational system in Oman. In Table 2 below, items 1, 2 and 3 demonstrate that respondents had high agreement (Means around 4) with the idea that research has a role on the development of the educational system especially 
at teacher level. This result is supported by interview data where 34 (94\%) interviewees believed that research has an important role in education. It was stated that "research helps in solving problems". One teacher stated that "research improves teacher's skills and develop the curriculum". Another teacher explained that "research helps in identifying and solving the societal difficulties that hinder efficiency of education, even sometimes predict some of problems so they can be avoided". It is also stated that "research helps students solve their problems". One teacher stated that "in addition to teaching, research should be part of teacher's task because of the renewable nature of teaching and educational problems and that the teacher is always available in the field and familiar with those problems".

On the other hand, negative statements i.e. items 4 and 5 in table 2 below (Means are 3.52 and 3.62 respectively), indicate that there was another group of participants who had negative perceptions of the role of research in the development of educational system. This result is supported in statements quoted in the open ended part of the questionnaire that expressed negative attitude towards research. One teacher wrote: "we should not depend on research findings and theories which are taught in universities because they are based on societies other than the Omani society so they are irrelevant to our society". Other statements of perceptions were: "research has no impact at all on teaching and learning because research recommendations were never considered for implementation", "the general opinion towards research is negative because it is not used at all... many research projects have been done but they have no accountability". Two of the interviewees also lacked belief in the supportive role of research in teaching. One interviewee asserted that "research is not important because the educational problems need political decision to be solved rather that teacher's decision".

The study findings in this regard concur with what is stated by the relevant literature e.g. Borg (2013), Gall et al (2007), Beycioglu et al (2010), Bevan (2004), Ektz (2006), and Mortimore (2000) that some teachers believe on the role of research in improving education and others do not.

Table 2: Participants' perceptions of role of research in education system

\begin{tabular}{|l|l|l|}
\hline No & Statement & Mean \\
\hline 1 & Research helps in improving my professional skills and capabilities & 4.06 \\
\hline 2 & Doing research helps me to understand the educational system & 3.96 \\
\hline 3 & Research strengthens the relationship between school and society & 3.91 \\
\hline 4 & Research has no impact on teaching and learning & 3.62 \\
\hline 5 & Doing research does not help me solve my students' problems & 3.52 \\
\hline
\end{tabular}

2. Extent to which teachers engage in research

Data analysed under this heading contribute to answering (RQ2). Engagement in research, as clarified by Borg (2013) means that teacher read 
published research and themselves do research. Both ideas are discussed below.

a. Extent to which teachers read published research

Data on extent to which teachers read published research was derived from responses to questionnaire Section 2, Question 1. As illustrated in Table 3 below, participants were not quite engaged in reading research: $36.8 \%$ maintained that they never read research papers, the majority $49.6 \%$ read between 1 and 5 papers per year, only 4.3\% read more than 5 papers per year and $9.3 \%$ provided no response.

b. Extent to which teachers do research

Data for this point which contribute alongside the previous analysis to (RQ2) was gathered from responses to questionnaire Section 2, Question 2. As illustrated in Table 3 below, participants were not quite engaged in doing research: $60.7 \%$ never done any research, $29.1 \%$ did 1 to 5 research projects per year, 2.2\% did more than 5 research projects per year and $8 \%$ provided no answers. This result agrees with AlFarsi (2006, p 28) who investigated 74 school teachers and comments that "I was really surprised to find few teachers had actually conducted classroom research". The obstacles that prevent teachers from carrying out research will be discussed in 4 below.

Table 3: Number of research read and done by participants per year.

\begin{tabular}{|c|c|c||c|c|c|}
\hline $\begin{array}{c}\text { Research papers } \\
\text { read per year }\end{array}$ & $\begin{array}{c}\text { number of } \\
\text { respondents }\end{array}$ & Percentage & $\begin{array}{c}\text { Research papers } \\
\text { done per year }\end{array}$ & $\begin{array}{c}\text { Number of } \\
\text { respondents }\end{array}$ & Percentage \\
\hline Nothing & 206 & 36.8 & Nothing & 340 & 60.7 \\
\hline $1-5$ & 278 & 49.6 & $1-5$ & 163 & 29.1 \\
\hline $6-10$ & 14 & 2.5 & $6-10$ & 6 & 1.1 \\
\hline More than 10 & 10 & 1.8 & More than 10 & 6 & 1.1 \\
\hline No answer & 52 & 9.3 & No answer & 45 & 8.0 \\
\hline Total & 560 & $100 \%$ & Total & 560 & $100 \%$ \\
\hline
\end{tabular}

\section{Teachers' attitudes towards doing research}

Questionnaire items 8, 10, 16, 21, 27 and 29 set up to provide data for this analysis which answers (RQ3). Teachers' attitudes towards TR, as illustrated in Table 4 below, are not quite positive and demonstrate divergent feelings towards research. For instance, item 4 with $($ Mean $=3.90)$ shows negative attitudes towards TR, participants regarded 'TR as a waste of time and effort'. Similar attitudes towards TR also explicit in item 5, $($ Mean $=$ 3.76) 'awards are not important and do not encourage me to do research', item 7 (Mean = 3.50) 'teachers do not need to do research' and item 9 (Mean $=3.41$ ) 'asking teachers to conduct research is unfair because it puts an extra load on them'. On the other hand, good attitude towards TR can be inferred from, item 8 (Mean = 3.46) 'I feel happy when I conduct research', and item 10 (Mean $=2.86$ ) 'I do not like research'. Deviating attitudes towards 
research also shown by previous research. Fore example, Beycioglu et al (2010) found that $68 \%$ of the participating teachers consider research findings and $32 \%$ of the participants had never done so since entering the teaching profession.

Table 4: Statements and Means of respondents' attitudes towards doing research.

\begin{tabular}{|c|c|c|}
\hline No. & Statement & Mean \\
\hline 1 & Doing research is a waste of time and effort & 3.90 \\
\hline 2 & Awards are not important and do not encourage me to do research & 3.76 \\
\hline 3 & Teachers do not need to do research & 3.50 \\
\hline 4 & I feel happy when I conduct research & 3.46 \\
\hline 5 & $\begin{array}{c}\text { Asking teachers to conduct research is unfair because } \\
\text { it puts an extra load on them }\end{array}$ & 3.41 \\
\hline 6 & I do not like doing research & 2.86 \\
\hline
\end{tabular}

4. Factors hinder teachers from conducting research

This analysis contributes to answering (RQ4). Data contributing to this point is collated from respondents' input for the questionnaire (question 1 and open-ended questions) and interviews where quotes from those two data sources are discussed below.

1. Lack of research knowledge and skills

Data derived from interviews and questionnaire demonstrates that teachers' lack of research skills and knowledge is one of the biggest obstacles that hinder participants' from doing research. Item 5 in the questionnaire demonstrates this (Mean $=3.64$ ) 'I feel uncomfortable for being unfamiliar with the procedure of research', Out of the 36 interviewed teachers, 11 (330.5\%) said that they had no idea at all about research. Others stated that their ideas about research are not clear, primitive, or they do not know the steps of doing research. Only 3 (8\%) interviewees said they know how to do research.

Participants' concerns about their lack of research knowledge and skills were mentioned around 105 times in the open-ended part of the questionnaire as an obstruct to doing research. The following statements that are quoted from the questionnaire prove such wary: "a large number of teachers do not know how to do research", "I am not familiar with the correct procedure of research", "I don't know anything about research skills", "I don't know the right way of doing research because I haven't done anything after finishing university". Other participants mentioned that being incompetent in computer skills and English deterred them from access to resources.

In addition, items 4, 7, 9, 11, 12, 13, 15, 17, 18, 20, 22, 24, 26, 28, 30, $31,33,34 \& 35$ in the questionnaire sought information from teachers about their comprehension of research skills. In table 5 below, items 11 to 19, for example- Means between 3.75 and 4.12, indicating high agreement- prove 
that participants lack very fundamental sense of research methodology such as the importance of research problem, interpretation of research results, referencing. The Means of positive statements i.e. 1 to 10, in addition to item number 20, indicate that there were some participants with reasonable understanding of research skills. This finding correlates with AlFarsi (2006) that lack of skills is a major obstacle to engagement of teachers in research.

Table 5: Statements and Means of respondents' research knowledge and skills.

\begin{tabular}{|c|c|c|}
\hline No. & Statement & Mean \\
\hline 1 & Literature review (electronic and paper-based) is important in research & 4.43 \\
\hline 2 & Table of content helps readers spot the right information easily & 4.38 \\
\hline 3 & Research reports have to be written in an accurate language and style & 4.37 \\
\hline 4 & Research tools have to be administered in order to have results & 4.29 \\
\hline 5 & Research questions are important & 4.28 \\
\hline 6 & Tables, charts and illustrations help readers understand the research content & 4.20 \\
\hline 7 & Selection of a sample is an important step in education research & 4.13 \\
\hline 8 & I have a good idea about educational research & 3.50 \\
\hline 9 & I can do educational research in the appropriate way & 3.17 \\
\hline 10 & Research can be done before setting its objectives & 1.96 \\
\hline 11 & It is not important to state a research problem when doing research & 4.12 \\
\hline 12 & Results interpretation is not important for research & 4.04 \\
\hline 13 & Referencing is not necessary for research & 3.92 \\
\hline 14 & I can arrive to important results without data analysis & 3.84 \\
\hline 15 & Testing of research validity and reliability is not important & 3.79 \\
\hline 16 & Statistical analysis of data is not important & 3.77 \\
\hline 17 & Recommendations are not important for research & 3.75 \\
\hline 18 & Hypotheses are not necessary for research & 3.60 \\
\hline 19 & Computer programs are not helpful for data analysis & 3.56 \\
\hline 20 & I can do research without using any research tools & 2.14 \\
\hline
\end{tabular}

2. Work conditions, time constraints and logistics

Work conditions and time constraints are interlocked and both mentioned around 400 times in the open-ended part of the questionnaire and interviews. Item 32 in the questionnaire asserts that majority of participants did not have time for doing research, (Mean $=3.97$ ) 'I am upset because I do not have enough time to do research'. Participants were overloaded with school work, their time was very tight in school and at home, so that they could not conduct research. A teacher asserted, "I am too much overloaded with teaching, assessment, out-of-class activities so that I can't do research or even think about doing it", another teacher mentioned that the teachers "are busy with teaching and other types of work... at home they have to go through other school duties in addition to their family and social responsibilities". Issues relating to logistics, mentioned more than 85 times, for example: deficiencies in resources, books, references, journals, computers, internet service, lack of financial support to cover expenses, 
uncomfortable formal regulations and nonexistence of practical assistance in terms of, for example, distribution and collection of questionnaires. A teacher wrote, "references are very rare. I tried many times to do research; the most difficulty I faced was finding useful references".

This finding on the impact of work conditions and time on teachers' engagement in research agrees with AlFarsi (2006) and Reis-Jorge (2007) findings that heavy workload, class size and extracurricular demands reported as hindering factors that prevent teachers from practicing research.

3. Conceptual factors

Ideas under this category were mentioned both in the interviews and open-ended section of the questionnaire around 60 times. Factors mentioned under this category include participants' understanding of and attitudes towards research and its role in development of educational system, their understanding of society's perception of research and its consequences on teacher-research. Examples of quotes about implementation of TR results and recommendations at the Ministry levels are: "first obstacle is that researches done by teachers are left inside drawers and never used..."; "I have the desire yet there is no encouragement by the Ministry in terms of applying the results because those results might be against the policies". Actually, this problem is reported as an area of dissatisfaction by Borg (2013 p 198) who states that despite the publication of the reports of the research done by the candidates that he supervised the Ministry of Education- sponsor of the project- did not take any attempt "to consider what changes it might suggest to the ways the Ministry operates". Other quotes by respondents are "the society is unaware of the importance of research... people are uncooperative... when questionnaires are distributed, they never come back... when we conduct interviews we get incorrect results and so on"; "many people think that research is interfering in others' personal lives and confidentiality".

4. Institutional factors

Institutional factors relate to participants' perception of the role of peers, schools and the Ministry of Education in supporting or hindering teachers from practicing in research- an idea expressed around 150 times. A major component of this category (mentioned around 100 times in the questionnaire and by interviewees) is that participants thought that there was no clear system of encouragement/rewards implemented by the $\mathrm{MoE}$ for supporting teacher research. One of the interviewees said that "I cannot see practical plan implemented by the Ministry for encouraging teachers to do research".

Some more statements that respondents made in the open-ended question were: There is "no support provided by educational institutions"," any clear support and encouragement... I have no idea about awards or 
promotions", "the surroundings, especially the school environment is not cooperative and not supportive", "school administrators do not encourage teacher research", and "the teacher is surrounded by many discouraging people".

Institutional support is crucial but unfortunately not provided by many school systems as previous research indicates. AlFarsi (2006) finds that lack of support by school is one of the major obstacles reported by the school teachers who participated in his study. Lytle and Cochran-Smith (1989 p 11) assert that "In many school systems, however, teachers have not been encouraged to work together on voluntary, self-initiated projects or speak out with authority about instructional, curricular and policy issues".

5. Participants' suggestions to engage in and with research

Both the interviewees and those who answered the open-ended part of the questionnaire suggested a number of ideas for more engagement in and with research. The suggestions are classified into three main categories below.

\section{Training}

Items 19 and 25 in the questionnaire focused on training and both gained high Means: item 19 (Mean $=3.91$ ), 'I need training on research methodology' and item 25 (Mean $=4.15$ ) 'I need a specialist to help and guide me when doing research'. Pre-service (undergraduate courses) and inservice training were mentioned by respondents more than 170 times in the open-ended part of the questionnaires and by all the 36 interviewed teachers as a main factor in helping teachers engage in research. One teacher stated "I suggest the establishment of in-service training courses on research methodology which is run by qualified specialists so that all teachers have a chance to attend". Many participants mentioned that they forgot the research skills that they studied at degree level so they need more training if they should do any research. Other suggestions include, teachers should be provided with a guidebook on how to conduct and write research in general, how to read and write internationally published research papers, and teachers' winning research papers should also be published and schools should be provided with copies of them so that teachers can refer to them as samples of well done research papers. approach

2. More systematic implementation of research results and rewarding

Participants suggested an implementation of a rewarding system that aims at establishing a research society where research becomes part of school life. This includes that "teacher research should be contextual-based and focus on real problems", "adaptation and adoption of well done research papers/projects and sound recommendations", and "rewards should be given to research practicing teachers". Ponte (2010 p 545) states that "teachers 
work in a culture that respects their opinions and the knowledge that they bring to the research experience". Alfarsy (2006) thinks that lack of reward is one of the major obstacles to engagement of teachers in research.

\section{Logistic support}

Many participants suggested the establishment of a research department in each educational district aiming at providing researcherteachers with professional support e.g. training, resources, guidance, distribution and collection of questionnaires and financial support. Schools should be provided with resources, PCs, internet service, and research material. Teachers should also have access to resource centres and libraries at Sultan Qaboos University and other research-based institutions. Other suggestions include "teachers should be given a chance to do research... the workload should be reduced a little bit, especially with non-pedagogical duties... it should be said that the teachers are more capable than anyone else to appreciate different types of educational problems".

\section{Discussion}

The study has attested that TR in Oman shares many of its trends and realities with TR as discussed in previous research e.g. Borg (2007 \& 2013), Hannon (1998), Worrall (2004) Reis-Jorge (2007), Allright (1997), Nunan (1997) and Barker (2005) especially in terms of teachers' engagement in, and with, research, obstacles that hinder teachers from doing research and the support they need to become competent practitioners. For instance, the study's finding that only a small number of teachers in Oman practice research concurs with Borg's $(2013,6)$ assertion that "teacher research is a minority activity". The factors that hinder teachers from engagement with/in research, which are also highlighted in previous research such as Hannon (1998), Worrall (2004) and Barker (2005), include conceptual inaccessibility, work conditions, knowledge, skills, attitudes, lack of autonomy to implement research results and lack of time. They entail practical or logistic areas and teachers' conceptions and attitudes. The effect of such factors is not limited to teachers who do not engage in research, but also entails teachers actively engaged in research. Statements such as "I feel that my research is valueless because its results and recommendations are not considered seriously especially when contradicting with school regulations such as the length of the teaching day and curriculum", indicates that even researcher teachers might stop doing research under circumstances such as feeling that their research does not lead to change in the educational system. The statement also indicates that conflicts of interest between researcher teacher and school systems may prevent teachers from doing TR. The study maintains that teachers' conceptions, involvement, and attitudes towards practicing research varies in a way that influences their engagement and the 
manner through which they benefit from research in classroom practice. It is obvious that some teachers are aware of the positive impact of TR on various areas of pedagogy, some feel unwilling to sustain their engagement in research, and others do not have the desire at all to be involved in practicing research.

Therefore, any endeavour to improve teachers' engagement with TR should address sustaining the engagement of researching teachers as well as encouraging less willing teachers to become effectively engaged in research. Such endeavour should also entail improving teachers' concepts, attitudes, and understandings as well as providing them with all logistical and practical conditions that help them become active and competent researchers. For example, in terms of attitudes and concepts, it should be clear to the teachers that if they want their research outcomes to be considered for implementation they should follow Nunan (1992 \&1997), Murray (1992) and Myers' (1987) view that TR is an approximation of university-based academic research that is taught in under/post graduate research skills courses and implemented by academics. Teachers, therefore, should be grounded in basic and applied science research in order to be competent to fulfill criteria set for teacher-research within this realm (Nunan, 1997; Myers, 1987 and Reis-Jorge, 2007). For those teachers who claim that they do not have the skills and work conditions that support practicing academic type of TR why not consider performing TR as exploratory practice Allwright (1997), Bissex \& Bullock (1987), Mohr \& Mclean (1987), Richardson (1994) and Cochran-Smith \& Lytle (1990). Teachers should be aware that exploratory practice is a pedagogy-oriented, research-like approach that helps maintain sustainability in teacher-research, though quality does not support change beyond teacher's limits (Allwright, 1997).

Participants' comments on the difficulties they encounter when conducting TR and the solutions they suggested overcoming them indicate that institutional support should be provided at three interconnected circles i.e. schools, educational districts and the Ministry. Participants explained that "the school culture is not supportive of teacher-research", reasons included "school management does not encourage teachers to do research", "shortage of time because of workloads", "discouraging peers", "lack of references, books and previous research", etc. Such statements demonstrate school support is at the core of the institutional support that teacher researchers need. Sustained and productive teacher engagement in research requires institutional commitment and a research culture that acknowledge all support structures (Barker, 2005 and Borg, 2007). Support at educational district and the Ministry level is required because it should help "towards a positive attitude and increased likelihood of participation in the innovation on the part of teachers" (Kennedy, 1987, p 165). In addition, the Ministry should 
establish a mechanism to facilitate and supervise the realization of TR results and the possible implementation of its recommendations. To summarize, educational districts and the Ministry should encourage schools to become active research centers by setting up policies, strategic planning and providing financial assistance.

\section{Conclusion}

Making TR a common, rather than a minority activity requires addressing all the factors that prevent teachers from engagement in research. Teachers' belief that TR does not lead to consequent change in the educational system requires further investigation to identify what indicates to teachers that their research is sound and trustworthy. Further research should also investigate what factors affect decision making in order to consider or not consider TR results and recommendations for change. The institutional support for TR from an institutional point of view is another potential research area, given the contextual application of this study.

\section{References:}

Adomßent, M.. Fischer, D., Godemann J., Herzig, C., Otte, I., Rieckmann, M., \& Timma, J. (2014). Emerging areas in research on higher education for sustainable development e management education, sustainable consumption and perspectives from Central and Eastern Europe. Journal of Cleaner Production, 62, 1-7.

Al Farsi, Basim Ahmed (2006) Omani teachers' attitudes toward classroom research. A Thesis in Teaching English to Speakers of Other Languages Presented to the faculty of the American University of Sharjah, College of Arts and Sciences in partial fulfillment of the requirements for the degree MASTER OF ARTS.

Allwright, D. (1997). Quality and sustainability in teacher research. TESOL Quarterly, 31(2), 368-370.

Anderson, G. L., \& Herr, K. (1999). The new paradigm wars: Is there room for rigorous practitioner knowledge in schools and universities? Educational Researcher, 28 (5), 15-21.

Atay, D. (2008). Teacher research for professional development. ELT Journal, 62 (2), 139-147.

Avalos, B. (2011). Teacher professional development in Teaching and Teacher Education over ten years. Teaching and Teacher Education, 27, 1020.

Barker, P (2005). Research in schools and colleges. National Educational Research Forum Working Paper 7.2. retrieved 2 August 2009 from http:www.nerf-uk.org/word/WP7.2ResearchinSchandCol.doc. 
Berthoff, A. (1987). The teacher as researcher. In Goswami, D. \& Stillman, P. (Eds.), Reclaiming the classroom: teacher research as an agency for change. Upper Montclair, NJ: Boynton/Cook Publishing.

Bevan, R. M. (2004). Filtering, fragmenting, and fiddling? Teachers' life cycles, and phases in their engagement with research. Teacher Development, 8, 325e340.

Beycioglu, K., Ozer, Niyazi \& Ugurlu, C. T. (2010).Teachers' views on educational research. Teaching and Teacher Education, 26, 1088-1093.

Britton, J. (1987). A quiet from research. In Goswami, D. \& Stillman, P. (Eds.), Reclaiming the classroom: teacher research as an agency for change. Upper Montclair, NJ: Boynton/Cook Publishing.

Bissex, G., \& Bullock, R. (1987). Seeing for ourselves: Case study research by teachers of writing. Portsmouth, HN: Heineman.

Borg, S. (2013). Teacher Research in Language Teaching: a critical analysis. Cambridge: Cambridge University Press.

Borg, S. (2007). Research engagement in English language teaching. Teaching and Teacher Education, 23, 731-747.

Borko, H., Jacobs, J. \& Koeliner, K. (2010). Contemporary approaches to teacher professional development. In Peterson, P., Baker, E. \& McGaw, B. (eds.), International Encyclopaedia of Education ( $3^{\text {rd }}$ ed) 7, 548-555. Oxford: Elsevier.

Buxton,C. A., Kayumova, S., Allexsaht-Snider, M. (2013). Creating space for democratic science teaching practices in middle schools: creating space for democratic science teaching practices in middle schools. Democracy and education, 21 (2), 1-10.

Campbell, K. H. (2013). A call to action: Why we need more practitioner research. Democracy and Education, 21 (2), 1-8.

Chandler-Olcott, K. (2002). Teacher Research as a Self-Extending System for Practitioners. Teacher Education Quarterly, winter, 23-38.

Cochran-Smith, M., \& Lytle, S. L. (1990). Research on teaching and teacher research: The issues that divide. Educational Researcher, 19(2), 2-11.

Dana, N. \& Yendol-Silva, D. (2003). Deconstructing inquiry: exploring the domains and contents of teachers' questions. Paper presented at the annual meeting of the American Educational Research Association, April, 2003, Chicago, IL.

Dana, N. F., Gimbert, B. \& Silva, D. Y., (2001). Teacher inquiry as a professional development for the 21 century in the United States. Change Transformation in Education, 4 (2), 51-59.

Dobber. M., Akkerman, S. F., Verloop, N., \& Vermunt, J. D. (2012) Student teachers' collaborative research: small-scale research projects during teacher education. Teaching and Teacher Education, 28, 609-617. 
Donnell, K. \& Harper, K. (2005) Inquiry in Teacher Education: Competing Agendas. Teacher Education Quarterly, Summer, 153-165.

Gall, M. D., Gall, J. P., \& Borg, W. R. (2007). Educational research: An introduction $\left(8^{\text {th }}\right.$ ed.). Berkshire: Allyn and Bacon.

Ektz, D. (2006). Primary School Teachers' Attitudes towards Educational Research. Educational Sciences: Theory \& Practice, 6 (2), 395-402.

Jurastaite-Harbison, E. \& Rex, A. R. (2005). Taking on a researcher's identity: Teacher learning in and through research participation. Linguistics and Education, 16, 425-454.

Kennedy, C. (1987). Innovation for a change: teacher development and innovation. ELT Journal, 41(3), 163-170.

Hannon, P. (1998). An ecological perspective on educational research. In J. Rudduck \& D. McIntyre (Eds.), Challenges for educational research (pp 144-149). London: SAGE.

Henson, R. (2001). The effect of participation in teacher research on teacher efficacy. Teaching and Teacher Education, 17, 819-836.

Kincheloe, J. (1991). Teachers as researchers: qualitative inquiry as path to empowerment. New York: The Falmer Press.

Loughran, J. (2010). A pedadogy of teacher education. In Peterson, P., Baker, E. \& McGaw, B. (Eds.), International Encyclopaedia of Education. Oxford: Elsevier, $3^{\text {rd }}$ edition 7, 587-591.

Lucas, P. (1988). An approach to research based teacher education through collaborative inquiry. Journal of Education for teaching, 14 (1), 55-73.

Lytle, S. \& Cochran-Smith, M. (1989). Teacher Research: Toward Clarifying the Concept. Quarterly, 11 (2), 1-15.

Lytle, S. \& Cochran-Smith, M. (1994). Inquiry, knowledge and practice. In Hollingsworth, S. Scockett, H. (eds.) Teacher research and educational reform (pp 22-51). Chicago, IL: University of Chicago Press.

Maeijer, P. C., Oolbekkink, H. W., Meirink, J. A. \& Ditte, L., (2013). Teacher research in secondary education: Effects on teachers' professional and school development, and issues of quality. International Journal of Educational Research, 57, 39-50.

McLaughlin, C. (2004). Partners in research: what's in it for you? Teacher Development, 8, 127e136.

Mills. G. E. (2003) Action Research: a guide for the teacher researcher. New Jersey: Pearson.

Ministry of Education (2009). Basic Education. Retrieved August 4, 2009, from the Ministry of Education web site: http//www.moe.gove.om/portal/sitebuilder/sites/EPS/English/MOE/BasicEd ucation.aspx

Mohr, M., \& Maclean, M. (1987). Working together: A guide for teacherresearchers. Urbana IL: National Council of Teachers of English. 
Mortimore, P. (2000). Does educational research matter? British Educational Research Journal, 26 (1), 5-24.

Murray, L. (1992). What is practitioner based enquiry? British Journal of InService Education, 18 (3) 191-196.

Myers, M. (1987). Institutionalizing inquiry. The Quarterly of the National Writing Project, 9 (3) 1-4.

Nunan, D. (1992). Research methods in language learning. Cambridge: Cambridge University Press.

Nunan, D. (1997). Developing standards for teacher-research in TESOL. TESOL Quarterly, 31(2), 365-367.

Parsons, R. \& Brown. K. (2002). Teacher as reflective practitioner and action researcher. Belmont, CA: Wadsworth/Thompson Learning.

Ponte, P. (2010). Action research as a tool for teachers' professional development. In Peterson, P., Baker, E. \& McGaw, B. (Eds.), International Encyclopaedia of Education, ( $3^{\text {rd }}$ ed), 7, 540-547. Oxford: Elsevier.

Richardson, V. (1994). Conducting research on practice. Educational Researcher, 23(5), 5-10.

Robson, C. (1993). Real world research. Oxford: Blackwell.

Reis-Jorge, J. (2007). Teachers' conceptions of teacher-research and selfperceptions as enquiring practitioners- a longitudinal case study. Teaching and Teacher Education, 23, 402-417.

Roulston, K., R. Legette, M. DeLoach, C. Bukhalter-Pittman, L. Cory, \& Grenier, R. (2005). Education: Mentoring and Community through Research. Research Studies in Music Education, 25: 1-23.

Rust, F. O., (2009) Teacher Research and the Problem of Practice. Teachers College Record, 111 (8), 1882-1893.

Simms, M. (2013). A Teacher-Educator Uses Action Research to Develop Culturally Conscious Curriculum Planners. Democracy and Education, 21 (2), $1-10$

Snow-Gerono, J. (2005). Professional development in a culture of inquiry: PDS teachers

identifythe benefits of professional learning communities. Teaching and Teacher Education, 21, 241-256.

Schulz, R. (2010). Inquiry-oriented teacher education. In Peterson, P., Baker, E. \& McGaw, B. (Eds.), International Encyclopaedia of Education. Oxford: Elsevier, $3^{\text {rd }}$ edition 7, 604-609.

Verma, G. and Mallick, K. (1999). Researching education: perspective and techniques. London: Falmer.

Webb, R. (1990). The origins and aspirations of practitioner research. In R. Webb (Ed.), Practitioner research in the primary school (12-33). London: The Falmer Press. 
Worrall, N. (2004). Trying to build a research culture in a school: Trying to find the right questions to ask. Teacher Development, 8, 137-148.

Zeichner, K. M. (2003). Teacher research as a professional development for P-12 education in the USA. Educational Action Research, 11 (2), 301-325. 